\title{
Maternal Intake of Astaxanthin Improved Hatchability of Fertilized Eggs Stored at High Temperature
}

\author{
Fumiya Saito and Kazumi Kita \\ United Graduate School of Agricultural Sciences, Iwate University, 3-18-8 Ueda, Morioka, Iwate 020-8550, Japan
}

\begin{abstract}
This work aimed at examining the interactive effect of maternal intake of astaxanthin (AX) and storage conditions (temperature and period) on the hatchability of fertilized eggs. Single comb White Leghorn laying hens were allocated to 4 groups with cocks. Experimental diets with 4 levels of AX were prepared by supplementing AX to a basal diet. AX levels were $0,5,10$ and $20 \mathrm{ppm}$. Eggs from each treatment group were stored for 0, 4, 7, 14 and 21 days at either 10 or $21^{\circ} \mathrm{C}$ of storage temperature with $70 \%$ of relative humidity. The number of hatched chicks was counted and un-hatched eggs were used to check the age of embryo death. When fertilized eggs were stored at $10^{\circ} \mathrm{C}$, the hatchability was kept at high level regardless of storage period. At $10^{\circ} \mathrm{C}$ of storage temperature, maternal intake of $\mathrm{AX}$ had no effect on the hatchability of fertilized eggs. On the other hand, the hatchability of eggs stored at $21^{\circ} \mathrm{C}$ was significantly lower than that at $10^{\circ} \mathrm{C}$, and lowered hatchability was restored by maternal intake of AX. Elevated levels of dietary AX from 5 to $20 \mathrm{ppm}$ gradually restrained the decrease in hatchability at $21^{\circ} \mathrm{C}$. On the mortality of embryos from 0 to 7 days of incubation, the interaction between dietary AX levels and storage temperature was significant. However, after 7 days of incubation, there was no significant interaction between dietary AX levels and storage temperature, and the effect of AX was not significant. These results suggest that the lowered hatchability of eggs stored at high temperature was restored by maternal feeding of dietary $\mathrm{AX}$, and the beneficial effect of AX may be effective at early stage of embryo development.
\end{abstract}

Key words: astaxanthin, hatchability, laying hens, Phaffia rhodozyma, storage temperature

J. Poult. Sci., 48: 33-39, 2011

\section{Introduction}

In the hatchery business, it is required to optimize the condition of egg storage to achieve the effective production of chicks. However, it was reported that the hatchability declined when the storage period of eggs exceeded 3 days irrespective of storage temperature (Reis et al., 1997). Storage period for longer than 10 days caused stress in embryos and resulted in excessive embryonic mortality during incubation (Mather and Laughlin, 1976, 1977, 1979). The rate of decline in hatchability after storage depended on the conditions during pre-incubation (Meijerhof, 1992). Temperature is one of various preincubation conditions, and the yolk in eggs stored at $30^{\circ} \mathrm{C}$ for 1 week showed higher thiobarbituric acid reactive substance (TBARS) value, which is known as a good index of lipid peroxidation, than that of eggs before storage (Yang et al., 2006). Surai et al. (2001) also suggested that, despite the important role of polyunsaturated fatty acids (PUFA) for the developing embryo, the presence of

Received: September 12, 2010, Accepted: October 26, 2010

Released Online Advance Publication: December 25, 2010

Correspondence: Dr. K. Kita, Faculty of Agricultural, Iwate Univer-

sity, 3-18-8 Ueda, Morioka, Iwate 020-8550, Japan.

(E-mail: kitak@iwate-u.ac.jp)
PUFA imparted a high degree of susceptibility to free radical inducing tissue damage as a result of lipid peroxidation. It was reported that carotenoid-enriched eggs were capable to protect the embryo from detrimental effects of free radicals and toxic effects of peroxidative lipids (Surai et al., 2001, 2003). Furtermore, Karadas et al. (2005) pointed out that maternal intake of dietary carotenoids may have important ramifications for the viability of offspring since the antioxidant and immunostimulatory roles of carotenoids were likely to be important during the immediate post-hatch period.

AX having red color is one of natural carotenoids and is known to be a powerful antioxidant with free radicalscavenging activity (Miki, 1991; Shimidzu et al., 1996). Kim et al. (2009) examined the protective action of AX against high glucose-induced oxidative stress in proximal tubular epithelial cells. In this report, it was shown that AX effectively suppressed TBARS value, superoxide $\left({ }^{\cdot} \mathrm{O}_{2}\right)$, nitric oxide $\left(\mathrm{NO}{ }^{\circ}\right)$ and peroxynitrite $\left(\mathrm{ONOO}^{-}\right)$. $\mathrm{AX}$ is contained in a great variety of crustaceans such as shrimp and crabs, the body surface of red sea bream, muscle of salmon (Katayama et al., 1974; Kitahara, 1985). AX is also abundantly contained in the red yeast Phaffia rhodozyma (PR) (Miller et al., 1976). When diets supplemented with PR were fed on laying hens, the pigmenta- 
tion of egg yolks was significantly enhanced (Johnson et al., 1980; Akiba et al., 2000a, b). Although there have been several reports examining the effect of carotenoids accumulated into eggs on the hatchability, little information regarding the interactive effect of yolk carotenoid and storage conditions of eggs has been available. In the present study, therefore, PR was given to laying hens, and then the interactive effect of maternal AX intake and storage conditions (period and temperature) of eggs on hatchability was examined.

\section{Materials and Methods}

Single comb White Leghorn chickens at 35-week-old were allocated to 4 pens $(4 \times 5 \mathrm{~m})$ holding 125 laying hens and 14 cocks. Body weight of laying hens at the commencement of experiment was $1.78 \pm 0.18 \mathrm{~kg}$. Fourteen hours of day length was provided. Free access to experimental diets and water was provided for 28 days of experimental period. Before feeding of experiment diets, all chickens were fed on a commercial diet for 10 days. A commercial diet free of pigment sources was used as a basal diet (crude protein $170 \mathrm{~g} / \mathrm{kg}$, metabolizable energy 2,920 kcal/kg, Nosan Co., Ltd., Yokohama, Japan). Experimental diets with 4 levels of $\operatorname{PR}(0,5,10$ and $20 \mathrm{ppm}$ of AX) were prepared by supplementing PR (AX concentration 4.0 mg/g, Mercian Feed Inc., Tomakomai, Japan) to the basal diet. All experiments were executed in Koiwai Farm Co., Ltd., (Shizukuishi, Japan) and approved by the Koiwai Animal Ethics Committee and conformed to Japanese legislation.

Body weight of laying hens was measured on the beginning and the end of experimental period. Feed consumption was recorded every 7 days during 28 days of experiment. Daily egg production was also recorded. Hundred eggs for measuring the hatchability were collected for 1528 days of experimental period and the same procedure was repeated 4 times. Beforehand, on day 13 of experimental period, eggs were collected and the content of AX in egg yolk was analyzed. Eggs from each group were stored for $0,4,7,14$ and 21 days at 10 or $21^{\circ} \mathrm{C}$ of storage temperature with $70 \%$ of relative humidity. During storage, the small end of eggs was placed downward, and all eggs were automatically turned every 1 hour. All eggs were pre-incubated at room temperature for 3 hours before transfer to the incubator, and incubated at $37.5^{\circ} \mathrm{C}$ with $60 \%$ of relative humidity. Eggs were automatically turned on every 1 hour. All eggs were candled after 7 and 19 days of incubation and discriminated infertile eggs. Eggs including a dead embryo were broken to check the age of death. Eggs were transferred in the hatching basket after 19 days of incubation. The number of chicks was counted after hatching and un-hatched eggs were broken to check the age of death, which was estimated according to the classification by Hamburger and Hamilton (1951).

AX in egg yolk was measured by the method of Surai and Speake (1998) and Pérez-Gálvez et al. (2008). The HPLC system was equipped Shimadzu LC-10AD pump and SPD-10A detector (Shimadzu Ltd., Kyoto, Japan). A Spherisorb type S3 ODS-2, $5 \mu \mathrm{m} \mathrm{C}_{18}$ reverse-phase column $(250 \times 4.6 \mathrm{~mm}$, Waters Co. Ltd., Tokyo, Japan $)$ was used with a mobile phase of solvent A (methanol/ acetonitrile/2-propanol, 49:49:2, v/v) and B (water). The linear gradient system was used as follows; $98 \%$ of solvent A for 3 minutes, $98 \%$ to $100 \%$ of solvent A for 7 minutes, 98\% of solvent A for 5 minutes, $100 \%$ to $98 \%$ of solvent A for 5 minutes. The flow rate was $1.0 \mathrm{ml} /$ minute and the wavelength of absorbance was $450 \mathrm{~nm}$. Carotenoids detected by HPLC were identified by comparing with commercial standards (CaroteNature $\mathrm{GmbH}$, Lupsingen, Switzerland).

Results were presented as mean \pm S.D. A GLM Procedure of SAS was used for statistical analysis (SAS Institute, 2000). Data concerning to hatchability and mortality were analyzed by 3-way ANOVA, and interactions among AX, storage temperature and storage period were analyzed. Except for these data, 1-way ANOVA was applied.

\section{Results}

Table 1 showed body weight gain, feed intake, egg production rate during experimental period and AX concentration in egg yolk on day 13 of feeding experiment. There was no significant difference in body weight gain, feed intake and egg production rate among varying die-

Table 1. Effect of maternal intake of astaxanthin (AX) on growth performance of laying hens and $\mathbf{A X}$ concentration in egg yolks

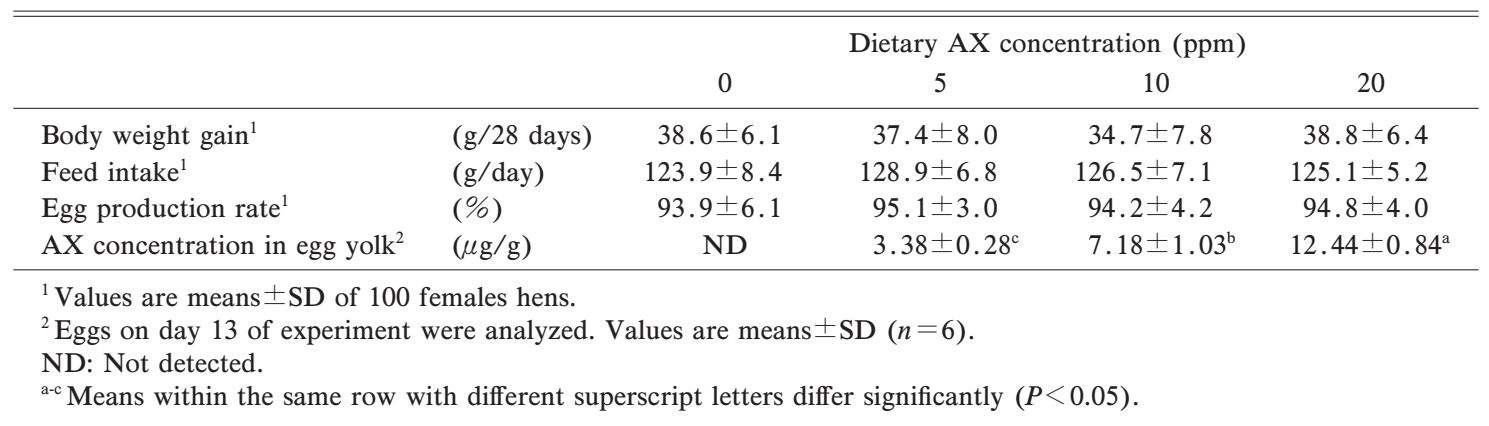


Table 2. Effect of astaxanthin (AX) transferred to egg yolk, storage temperature and storage period on the hatchability $(\%)^{1}$ of fertilized eggs

\begin{tabular}{|c|c|c|c|c|c|c|}
\hline \multirow[b]{2}{*}{$\begin{array}{c}\text { Storage } \\
\text { temperature }\end{array}$} & \multirow[b]{2}{*}{$\begin{array}{l}\text { Dietary AX } \\
\text { level (ppm) }\end{array}$} & \multicolumn{4}{|c|}{ Storage period } & \multirow[b]{2}{*}{ Average } \\
\hline & & 4 days & 7 days & 14 days & 21 days & \\
\hline \multirow[t]{5}{*}{$10^{\circ} \mathrm{C}$} & 0 & $89.3 \pm 1.9$ & $87.5 \pm 2.3$ & $86.3 \pm 1.6$ & $72.8 \pm 0.4$ & $83.9 \pm 7.0 *$ \\
\hline & 5 & $89.0 \pm 1.7$ & $88.5 \pm 1.8$ & $84.8 \pm 1.8$ & $73.8 \pm 2.6$ & $84.0 \pm 6.7 *$ \\
\hline & 10 & $90.3 \pm 1.9$ & $87.8 \pm 4.1$ & $86.3 \pm 1.5$ & $71.8 \pm 1.5$ & $84.0 \pm 7.9^{*}$ \\
\hline & 20 & $91.0 \pm 1.6$ & $89.0 \pm 2.1$ & $86.5 \pm 1.7$ & $72.3 \pm 2.6$ & $84.7 \pm 7.9 *$ \\
\hline & Average & $89.9 \pm 2.0$ & $88.2 \pm 2.9$ & $85.9 \pm 1.8$ & $72.6 \pm 2.2$ & \\
\hline \multirow[t]{5}{*}{$21^{\circ} \mathrm{C}$} & 0 & $81.0 \pm 1.9$ & $78.5 \pm 2.1$ & $74.3 \pm 1.8$ & $60.8 \pm 3.0$ & $73.6 \pm 8.4^{\mathrm{d}}$ \\
\hline & 5 & $82.3 \pm 2.4$ & $81.3 \pm 2.9$ & $76.3 \pm 3.3$ & $62.5 \pm 3.0$ & $75.6 \pm 8.7^{\mathrm{c}}$ \\
\hline & 10 & $83.8 \pm 1.3$ & $83.0 \pm 2.7$ & $76.8 \pm 3.9$ & $67.5 \pm 3.2$ & $77.8 \pm 7.4^{\mathrm{b}}$ \\
\hline & 20 & $84.0 \pm 0.7$ & $84.5 \pm 3.2$ & $81.5 \pm 2.3$ & $68.8 \pm 1.6$ & $79.7 \pm 7.0^{\mathrm{a}}$ \\
\hline & Average & $82.8 \pm 2.1$ & $81.8 \pm 3.7$ & $77.2 \pm 4.1$ & $64.9 \pm 4.5$ & \\
\hline \multicolumn{2}{|l|}{ Effect } & \multicolumn{3}{|c|}{ Probability } & & \\
\hline \multicolumn{2}{|l|}{$\mathrm{AX}$} & \multicolumn{3}{|c|}{0.001} & & \\
\hline \multicolumn{2}{|l|}{ Temperature } & \multicolumn{3}{|c|}{0.001} & & \\
\hline \multicolumn{2}{|c|}{ Period } & \multicolumn{3}{|c|}{0.001} & & \\
\hline \multicolumn{2}{|c|}{$\mathrm{AX} \times$ Temperature } & \multicolumn{3}{|c|}{0.001} & & \\
\hline \multicolumn{2}{|c|}{$\mathrm{AX} \times$ Period } & \multicolumn{3}{|c|}{0.980} & & \\
\hline \multicolumn{2}{|c|}{ Temperature $\times$ Period } & \multicolumn{3}{|c|}{0.356} & & \\
\hline \multicolumn{2}{|c|}{$\mathrm{AX} \times$ Temperature $\times$ Period } & \multicolumn{3}{|c|}{0.403} & & \\
\hline
\end{tabular}

Values are means \pm SD of 4 replicates with 100 eggs observations.

Before storage, the hatchability of eggs in $0,5,10$ and $20 \mathrm{ppm}$ of dietary AX groups were $90.0 \pm 2.2,90.3 \pm 1.3,89.5 \pm$ 0.6 and $89.8 \pm 0.5(\%)$, respectively.

${ }^{1}$ Number of hatched eggs/Number of eggs in a incubator $\times 100$.

${ }^{\mathrm{a}-\mathrm{b}}$ Means within the same temperature with different superscript letters differ significantly $(P<0.05)$.

* Means within the same AX level differ significantly $(P<0.05)$.

tary AX concentrations. AX concentration in egg yolk was increased along with an elevation of dietary AX concentration.

Table 2 showed the hatchability of fertilized egg stored at different temperature and storage period. Significant interaction between dietary AX level and storage temperature was observed. The hatchability was reduced by high storage temperature at $21^{\circ} \mathrm{C}$ regardless of different dietary AX levels. At $10^{\circ} \mathrm{C}$ of storage temperature, there was no significant differences in hatchability among varying dietary AX levels. On the other hand, in the $21^{\circ} \mathrm{C}$ storage groups, elevating dietary AX levels from 5 to $20 \mathrm{ppm}$ restrained the decrease in hatchability.

Table 3 showed the mortality of embryos from 0 to 7 days of incubation. Significant interaction between dietary AX level and storage temperature was observed in the mortality. When eggs were stored at $21^{\circ} \mathrm{C}$, the mortality was significantly higher than that of eggs stored at $10^{\circ} \mathrm{C}$. Although, maternal intake of dietary AX did not affect the mortality of embryos in eggs stored at $10^{\circ} \mathrm{C}, \mathrm{AX}$ successfully suppressed the increase in mortality at $21^{\circ} \mathrm{C}$ of storage temperature. An interaction between storage temperature and storage period on the mortality from 0 to 7 days of incubation was also significant. When fertilized eggs were stored at $21^{\circ} \mathrm{C}$, the increase in mortality was accelerated along with the length of storage period compared to those stored at $10^{\circ} \mathrm{C}$. On each storage period, high storage temperature elevated the mortality.

Table 4 showed the mortality of embryos from 7 to 19 days of incubation. No interaction between maternal intake of dietary AX and storage temperature was observed. There was a significant interaction between storage temperature and storage period. When eggs were stored at $10^{\circ} \mathrm{C}$, the low level of mortality was kept until 14 days of storage period. But the mortality of embryos in eggs stored for 21 day was significantly higher than those for 14 days. Compared to $10^{\circ} \mathrm{C}$ of storage temperature, the early elevation of mortality was observed when eggs were stored at $21{ }^{\circ} \mathrm{C}$.

Table 5 showed the mortality after 19 days of incubation. No interaction between maternal intake of dietary AX and storage temperature was observed. Significant interaction between storage temperature and storage period was found. When eggs were stored for more than 4 days, the mortality of embryo in eggs stored at $21^{\circ} \mathrm{C}$ was significantly higher than that in the $10^{\circ} \mathrm{C}$ group. 
Table 3. Effect of astaxanthin (AX) transferred to egg yolk, storage temperature and storage period on the mortality $(\%)^{1}$ of embryos from 0 to 7 days of incubation

\begin{tabular}{|c|c|c|c|c|c|c|}
\hline \multirow[b]{2}{*}{$\begin{array}{c}\text { Storage } \\
\text { temperature }\end{array}$} & \multirow[b]{2}{*}{$\begin{array}{l}\text { Dietary AX } \\
\text { level (ppm) }\end{array}$} & \multicolumn{4}{|c|}{ Storage period } & \multirow[b]{2}{*}{ Average } \\
\hline & & 4 days & 7 days & 14 days & 21 days & \\
\hline \multirow[t]{5}{*}{$10^{\circ} \mathrm{C}$} & 0 & $4.3 \pm 0.4$ & $5.3 \pm 1.1$ & $4.8 \pm 0.8$ & $11.5 \pm 2.3$ & $6.4 \pm 3.4^{*}$ \\
\hline & 5 & $3.8 \pm 0.8$ & $5.0 \pm 0.7$ & $5.5 \pm 1.1$ & $12.0 \pm 1.9$ & $6.6 \pm 3.5^{*}$ \\
\hline & 10 & $4.0 \pm 0.7$ & $4.5 \pm 2.2$ & $5.3 \pm 0.8$ & $11.3 \pm 1.8$ & $6.3 \pm 3.4^{*}$ \\
\hline & 20 & $2.8 \pm 1.1$ & $4.0 \pm 1.6$ & $4.8 \pm 0.8$ & $10.8 \pm 1.3$ & $5.6 \pm 3.4^{*}$ \\
\hline & Average & $3.7 \pm 1.0^{\mathrm{y}, \#}$ & $4.7 \pm 1.6^{\mathrm{xy}, \#}$ & $5.1 \pm 1.0^{\mathrm{x}, \#}$ & $11.4 \pm 2.0^{\mathrm{w}, \#}$ & \\
\hline \multirow[t]{5}{*}{$21^{\circ} \mathrm{C}$} & 0 & $6.8 \pm 1.1$ & $8.5 \pm 1.1$ & $10.3 \pm 2.3$ & $17.8 \pm 2.9$ & $10.8 \pm 4.8^{\mathrm{a}}$ \\
\hline & 5 & $5.5 \pm 1.1$ & $7.3 \pm 1.1$ & $9.3 \pm 1.9$ & $17.5 \pm 1.5$ & $9.9 \pm 5.0^{\mathrm{ab}}$ \\
\hline & 10 & $5.3 \pm 0.8$ & $7.3 \pm 1.1$ & $9.5 \pm 1.1$ & $13.8 \pm 1.9$ & $8.9 \pm 3.5^{b}$ \\
\hline & 20 & $5.3 \pm 1.1$ & $6.0 \pm 1.2$ & $5.5 \pm 1.1$ & $13.0 \pm 1.2$ & $7.4 \pm 3.5^{\mathrm{c}}$ \\
\hline & Average & $5.7 \pm 1.3^{z}$ & $7.3 \pm 1.5^{\mathrm{y}}$ & $8.6 \pm 2.6^{x}$ & $15.5 \pm 3.0^{\mathrm{w}}$ & \\
\hline \multicolumn{2}{|l|}{ Effect } & \multicolumn{3}{|c|}{ Probability } & & \\
\hline \multicolumn{2}{|l|}{$\mathrm{AX}$} & \multicolumn{3}{|c|}{0.001} & & \\
\hline \multicolumn{2}{|l|}{ Temperature } & \multicolumn{3}{|c|}{0.001} & & \\
\hline \multicolumn{2}{|c|}{ Period } & \multicolumn{3}{|c|}{0.001} & & \\
\hline \multicolumn{2}{|c|}{$\mathrm{AX} \times$ Temperature } & \multicolumn{3}{|c|}{0.024} & & \\
\hline \multicolumn{2}{|c|}{$\mathrm{AX} \times$ Period } & \multicolumn{3}{|c|}{0.443} & & \\
\hline \multicolumn{2}{|c|}{ Temperature $\times$ Period } & \multicolumn{3}{|c|}{0.049} & & \\
\hline \multicolumn{2}{|c|}{ AX $\times$ Temperature $\times$ Period } & \multicolumn{3}{|c|}{0.367} & & \\
\hline
\end{tabular}

Values are means \pm SD of 4 replicates with 100 eggs observations.

Before storage, the mortality from 0 to 7 day of incubation in $0,5,10$ and $20 \mathrm{ppm}$ of dietary AX gtoup were 5.0 \pm 1.4 , $4.0 \pm 0.8,5.3 \pm 1.0$ and $3.5 \pm 1.3(\%)$, respectively.

${ }^{1}$ Number of mortality/Number of eggs in incubator $\times 100$.

${ }^{\mathrm{a}-\mathrm{b}}$ Means within the same temperature with different superscript letters differ significantly $(P<0.05)$.

${ }^{\text {w-z }}$ Means within the same temperature with different superscript letters differ significantly $(P<0.05)$.

* Means within the same AX level differ significantly $(P<0.05)$.

${ }^{\#}$ Means within the same storage period differ significantly $(P<0.05)$.

\section{Discussion}

In the present study, we investigated the influence of long term storage of fertilized eggs at different temperature on the hatchability of eggs from laying hens given varying dietary AX levels. As shown in Table 2, there was an interaction between maternal intake of dietary $\mathrm{AX}$ and storage temperature of fertilized eggs on the hatchability. When fertilized eggs were stored at $10^{\circ} \mathrm{C}$, the hatchability was kept at high level, which was in good agreement with studies reported by some researchers (Olsen and Haynes, 1948; Eyng and Nash, 1962; Mayes and Takeballi, 1984; Meijerhof, 1992). These results suggest that storage temperature at $10^{\circ} \mathrm{C}$ seems to be suitable to keep high hatchability of fertilized eggs. As shown in Table 1, maternal intake of dietary AX to laying hens successfully increased the accumulation of AX in egg yolk and the accumulated amount of yolk AX depended on dietary AX levels. But accumulated AX in egg yolk have no effect on hatchability of fertilized eggs stored at low temperature (Table 2). Similarly, the high hatchability of fertilized eggs was not further improved by maternal ingestion of $\beta$-carotene
(Darmon et al., 1984).

On the other hand, the hatchability of fertilized eggs stored at $21^{\circ} \mathrm{C}$ was significantly lower than that at $10^{\circ} \mathrm{C}$, and lowered hatchability was restored by maternal intake of dietary AX (Table 2). Yang et al. (2006) reported that egg yolks stored at high temperature showed the high value for TBARS, which is good index of lipid peroxidation and oxidative stress (Lohakare et al., 2004), compared to eggs before storage. From these findings, it would be suggested that the exposure of high temperature to fertilized eggs steadily increased peroxidative products. Oxidative stress arising from the peroxidation of free radicals is likely to be most prominent in rapidly growing embryos because of their high levels of oxidative metabolism (Vleck and Bucher, 1998). The use of fish oil in the broiler breeder diet resulted in lower hatchability compared with the eggs from hens fed diets containing soybean oil (Pappas et al., 2006), suggesting that the higher mortality caused by the ingestion of fish oil may be due to the high level of PUFA and the associated increase in free radicals generated.

As shown in Table 2, it was obvious that the lowered 
Table 4. Effect of astaxanthin (AX) transferred to egg yolk, storage temperature and storage period on the mortality $(\%)^{1}$ of embryos from 7 to 19 days of incubation

\begin{tabular}{|c|c|c|c|c|c|c|}
\hline \multirow[b]{2}{*}{$\begin{array}{c}\text { Storage } \\
\text { temperature }\end{array}$} & \multirow[b]{2}{*}{$\begin{array}{l}\text { Dietary AX } \\
\text { level (ppm) }\end{array}$} & \multicolumn{4}{|c|}{ Storage period } & \multirow[b]{2}{*}{ Average } \\
\hline & & 4 days & 7 days & 14 days & 21 days & \\
\hline \multirow[t]{5}{*}{$10^{\circ} \mathrm{C}$} & 0 & $5.0 \pm 1.9$ & $5.3 \pm 1.9$ & $5.5 \pm 1.1$ & $12.5 \pm 2.6$ & $7.1 \pm 3.8$ \\
\hline & 5 & $5.5 \pm 1.1$ & $5.0 \pm 1.2$ & $5.8 \pm 1.3$ & $11.3 \pm 2.9$ & $6.9 \pm 3.2$ \\
\hline & 10 & $4.8 \pm 1.5$ & $5.8 \pm 1.5$ & $4.8 \pm 0.8$ & $14.3 \pm 1.5$ & $7.4 \pm 4.4$ \\
\hline & 20 & $4.3 \pm 1.6$ & $5.0 \pm 1.2$ & $4.5 \pm 1.5$ & $13.5 \pm 1.7$ & $6.8 \pm 4.3$ \\
\hline & Average & $4.9 \pm 1.7^{\mathrm{y}, \#}$ & $5.3 \pm 1.6^{\mathrm{y}, \#}$ & $5.1 \pm 1.4^{\mathrm{y}, \#}$ & $12.9 \pm 2.6^{x}$ & \\
\hline \multirow[t]{5}{*}{$21^{\circ} \mathrm{C}$} & 0 & $7.5 \pm 1.1$ & $9.3 \pm 0.8$ & $10.0 \pm 0.7$ & $15.8 \pm 1.5$ & $10.6 \pm 3.4$ \\
\hline & 5 & $7.8 \pm 0.8$ & $8.5 \pm 1.7$ & $9.3 \pm 0.8$ & $14.8 \pm 2.2$ & $10.1 \pm 3.2$ \\
\hline & 10 & $7.3 \pm 0.8$ & $6.8 \pm 2.4$ & $9.3 \pm 1.8$ & $13.0 \pm 0.7$ & $9.1 \pm 3.0$ \\
\hline & 20 & $7.0 \pm 0.7$ & $6.0 \pm 2.1$ & $9.0 \pm 1.9$ & $12.3 \pm 0.8$ & $8.6 \pm 2.9$ \\
\hline & Average & $7.4 \pm 1.0^{z}$ & $7.6 \pm 2.3^{z}$ & $9.4 \pm 1.5^{y}$ & $13.9 \pm 2.1^{x}$ & \\
\hline \multicolumn{2}{|l|}{ Effect } & \multicolumn{3}{|c|}{ Probability } & & \\
\hline \multicolumn{2}{|l|}{$\mathrm{AX}$} & \multicolumn{3}{|c|}{0.077} & & \\
\hline \multicolumn{2}{|l|}{ Temperature } & \multicolumn{3}{|c|}{0.001} & & \\
\hline \multicolumn{2}{|c|}{ Period } & \multicolumn{3}{|c|}{0.001} & & \\
\hline \multicolumn{2}{|c|}{$\mathrm{AX} \times$ Temperature } & \multicolumn{3}{|c|}{0.078} & & \\
\hline \multicolumn{2}{|c|}{$\mathrm{AX} \times$ Period } & \multicolumn{3}{|c|}{0.978} & & \\
\hline \multicolumn{2}{|c|}{ Temperature $\times$ Period } & \multicolumn{3}{|c|}{0.007} & & \\
\hline \multicolumn{2}{|c|}{$\mathrm{AX} \times$ Temperature $\times$ Period } & \multicolumn{3}{|c|}{0.248} & & \\
\hline
\end{tabular}

Values are means \pm SD of 4 replicates with 100 eggs observations.

Before storage, the mortality from 7 to 19 day of incubation in 0, 5, 10 and $20 \mathrm{ppm}$ of dietary AX group were $4.0 \pm$ $0.8,4.3 \pm 0.5,4.5 \pm 1.0$ and $4.5 \pm 0.6(\%)$, respectively.

${ }^{1}$ Number of mortality/Number of eggs in incubator $\times 100$.

${ }^{\mathrm{x}-\mathrm{z}}$ Means within the same temperature with different superscript letters differ significantly $(P<0.05)$.

${ }^{*}$ Means within the same storage period differ significantly $(P<0.05)$.

hatchability by high storage temperature was restored by maternal intake of dietary AX to laying hens. Moreover, elevated levels of dietary AX from 5 to 20 ppm gradually restrained the decrease in hatchability. When laying hens were given dietary AX, the increase in yolk AX depended on dietary AX levels (Table 1). Surai and Speake (1998) reported that the accumulation of carotenoids in the tissue of embryos was elevated along with yolk carotenoid levels and significant reduction of susceptibility to in vitro peroxidation was associated with carotenoids accumulated in yolks. Yang et al. (2006) reported when egg yolks were stored at high temperature, the high value for TBARS decreased with increasing amount of AX concentration in egg yolk. These results suggested that the beneficial effect of maternal intake of AX to retrain the lowered hatchability seemed to be due to $\mathrm{AX}$ transferred from laying hens to egg yolks.

As shown in Table 3, the significant interaction between dietary AX levels and storage temperature on the mortality of embryos from 0 to 7 days of incubation was observed. Similar interaction was found in hatchability of fertilized eggs (Table 2). However, after 7 days of incubation, there was no significant interaction between dietary AX levels and storage temperature (Tables 4 and 5).
These results suggest that the beneficial effect of AX in egg yolk may be brought out at early stages of embryo development. Namekawa et al. (2010) reported that impaired development on early stages of bovine embryos exposed to heat stress was ameliorated by $\mathrm{AX}$ added to the culture medium. However, the mechanism of AX to restrain the higher mortality especially at early stages of embryo development has not been clarified, and this issue should be elucidated in the future. 
Table 5. Effect of astaxanthin (AX) transferred to egg yolk, storage temperature and storage period on the mortality $(\%)^{1}$ of embryos after 19 days of incubation

\begin{tabular}{|c|c|c|c|c|c|c|}
\hline \multirow[b]{2}{*}{$\begin{array}{c}\text { Storage } \\
\text { temperature }\end{array}$} & \multirow[b]{2}{*}{$\begin{array}{l}\text { Dietary AX } \\
\text { level (ppm) }\end{array}$} & \multicolumn{4}{|c|}{ Storage period } & \multirow[b]{2}{*}{ Average } \\
\hline & & 4 days & 7 days & 14 days & 21 days & \\
\hline \multirow[t]{5}{*}{$10^{\circ} \mathrm{C}$} & 0 & $1.5 \pm 0.5$ & $2.0 \pm 0.7$ & $3.5 \pm 1.1$ & $3.3 \pm 0.8$ & $2.6 \pm 1.2$ \\
\hline & 5 & $1.8 \pm 0.4$ & $1.5 \pm 0.5$ & $4.0 \pm 0.7$ & $3.0 \pm 0.7$ & $2.6 \pm 1.2$ \\
\hline & 10 & $1.0 \pm 0.7$ & $2.0 \pm 0.7$ & $3.8 \pm 0.8$ & $2.8 \pm 1.1$ & $2.4 \pm 1.4$ \\
\hline & 20 & $2.0 \pm 0.7$ & $2.0 \pm 0.7$ & $4.3 \pm 0.4$ & $3.5 \pm 0.5$ & $2.9 \pm 1.2$ \\
\hline & Average & $1.6 \pm 0.7^{z, \#}$ & $1.9 \pm 0.7^{\mathrm{z}, \#}$ & $3.9 \pm 0.9^{\mathrm{x}, \#}$ & $3.1 \pm 0.9^{\mathrm{y}, \#}$ & \\
\hline \multirow[t]{5}{*}{$21^{\circ} \mathrm{C}$} & 0 & $4.8 \pm 0.8$ & $3.8 \pm 0.8$ & $5.5 \pm 0.5$ & $5.8 \pm 0.8$ & $4.9 \pm 1.1$ \\
\hline & 5 & $4.5 \pm 1.1$ & $3.0 \pm 0.7$ & $5.3 \pm 0.8$ & $5.3 \pm 0.4$ & $4.5 \pm 1.3$ \\
\hline & 10 & $3.8 \pm 0.8$ & $3.0 \pm 0.7$ & $4.5 \pm 1.1$ & $5.8 \pm 0.8$ & $4.3 \pm 1.4$ \\
\hline & 20 & $3.8 \pm 0.4$ & $3.5 \pm 1.1$ & $4.0 \pm 1.2$ & $6.0 \pm 1.2$ & $4.3 \pm 1.5$ \\
\hline & Average & $4.2 \pm 1.0^{y}$ & $3.3 \pm 1.0^{\mathrm{z}}$ & $4.8 \pm 1.2^{\mathrm{y}}$ & $5.7 \pm 1.0^{\mathrm{x}}$ & \\
\hline \multicolumn{2}{|l|}{ Effect } & \multicolumn{3}{|c|}{ Probability } & & \\
\hline \multicolumn{2}{|l|}{$\mathrm{AX}$} & \multicolumn{3}{|c|}{0.296} & & \\
\hline \multicolumn{2}{|l|}{ Temperature } & \multicolumn{3}{|c|}{0.001} & & \\
\hline \multicolumn{2}{|c|}{ Period } & \multicolumn{3}{|c|}{0.001} & & \\
\hline \multicolumn{2}{|c|}{$\mathrm{AX} \times$ Temperature } & \multicolumn{3}{|c|}{0.210} & & \\
\hline \multicolumn{2}{|c|}{$\mathrm{AX} \times$ Period } & \multicolumn{3}{|c|}{0.762} & & \\
\hline \multicolumn{2}{|c|}{ Temperature $\times$ Period } & \multicolumn{3}{|c|}{0.001} & & \\
\hline \multicolumn{2}{|c|}{$\mathrm{AX} \times$ Temperature $\times$ Period } & \multicolumn{3}{|c|}{0.776} & & \\
\hline
\end{tabular}

Values are means \pm SD of 4 replicates with 100 eggs observations.

Before storage, the mortality after 19 day of incubation in $0,5,10$ and $20 \mathrm{ppm}$ of dietary AX group were $1.0 \pm 0.8,1.5$ $\pm 1.7,0.8 \pm 1.0$ and $2.3 \pm 1.0(\%)$, respectively.

${ }^{1}$ Number of mortality/Number of eggs in incubator $\times 100$.

${ }^{\mathrm{x}-\mathrm{z}}$ Means within the same temperature with different superscript letters differ significantly $(P<0.05)$.

${ }^{\#}$ Means within the same storage period differ significantly $(P<0.05)$.

\section{References}

Akiba Y, Sato K, Takahashi K, Takahahi Y, Furuki A, Konashi S, Nishida H, Tsunekawa H, Hayasaka Y and Nagao H. Pigmentation of egg yolk with Yeast Phaffia rhodozyma containing high concentration of astaxanthin in laying hens fed on a low-carotenoid diet. Journal of Poultry Science, 37: 77 -85.2000 a.

Akiba Y, Sato K, Takahashi K, Toyomizu M, Takahahi Y, Konashi S, Nishida H, Tsunekawa H, Hayasaka $\mathrm{Y}$ and Nagao H. Improved pigmentation of egg yolk by feeding of Yeast Phaffia rhodozyma containing high concentration of astaxanthin in laying hens. Journal of Poultry Science, 37: 162-170. 2000b.

Damron BL, Goodson SR, Harms RH, Janky DM and Wilson HR. Beta-carotene supplementation of laying hen diets. British Poultry Science, 25: 349-352. 1984.

Eyng AJ and Nash D. The effect of egg storage on hatchability. British Poultry Science, 3: 81-87. 1962.

Hamburger V and Hamilton HL. A series of normal stages in the development of the chick embryo. Journal of Morphology, 88: 49-87. 1951.

Johnson EA, Lewis MJ and Grau CR. Pigmentaion of egg yolks with astaxanthin from the Yeast Phaffia rhodozyma. Poultry Science, 59: 1777-1782. 1980.

Karadas F, Pappas AC, Surai PF and Speake BK. Embryonic development within carotenoid-enriched eggs influences the post-hatch carotenoid status of the chicken. Comparative Biochemistry and Physiology, 141: 244-251. 2005.

Katayama T, Miyahara T, Tanaka Y, Sameshima M, Simpson $\mathrm{KL}$ and Chishester CO. The biosynthesis of astaxanthin -XV. The carotenoids in Chidai, red sea bream, Evynnis japonica Tanaka and [the incorporation of labeled astaxanthin from the diet of the red sea bream] to their body astaxanthin. Bulletin of the Japanese Society of Scientific Fisheries, 40: 97-103. 1974.

Kim YJ, Kim YA and Yokozawa T. Protection against oxidative stress, inflammation, and apoptosis of high-glucose-exposed proximal tubular epithelial cells by astaxanthin. Journal of Agricultural and Food Chemistry, 57: 8793-8797. 2009.

Kitahara T. Behavior of carotenoids in the masu salmon Oncorhynchus masou during anadromous migration. Bulletin of the Japanese Society of Scientific Fisheries, 51: 253-255. 1985.

Lohakare JD, Hahn TW, Shim YH, Choi JY and Chae BJ. Effects of feeding methods (feed vs. water) of vitamin $\mathrm{E}$ on growth performance and meat quality of broilers. Asian Australasian Journal of Animal Sciences, 17: 1260-1265. 2004.

Mather CM and Laughlin KF. Storage of hatching eggs: The effect on total incubation period. British Poultry Science, 17: 471-479. 1976. 
Mather CM and Laughlin KF. Storage of hatching eggs: The effect on early embryonic development. British Poultry Science, 18: 597-603. 1977.

Mather CM and Laughlin KF. Storage of hatching eggs: The interaction between parental age and early embryonic development. British Poultry Science, 20: 595-604. 1979.

Mayes FJ and Takeballi MA. Storage of the eggs of the fowl (Gallus domesticus) before incubation: a review. World's Poultry Science Journal, 40: 131-140. 1984.

Meijerhof R. Pre-incubation holding of hatching eggs. World's Poultry Science Journal, 48: 57-68. 1992.

Miki W. Biological functions and activities of animal carotenoids. Pure and Applied Chemistry, 63: 141-146. 1991.

Miller MW, Yoneyama M and Soneda M, Phaffia, a new yeast genus in the Deuteromycotina (Blastomycetes). International Journal of Systematic Bacteriology, 26: 286-291. 1976.

Namekawa T, Ikeda S, Sugimoto $\mathbf{M}$ and Kume S. Effects of astaxanthin-containing oil on development and stress-related gene expression of bovine embryos exposed to heat stress. Reproduction in Domestic Animals, 45: 387-391, 2010.

Olsen MW and Haynes SK. The effect of different holding temperatures on the hatchability of hens' eggs. Poultry Science, 27: 420-426. 1948.

Pappas AC, Acamovic T, Sparks NH, Surai PF and McDevitt RM. Effects of supplementing broiler breeder diets with organoselenium compounds and polyunsaturated fatty acids on hatchability. Poultry Science, 85: 1584-1593. 2006.

Pérez-Gálvez A, Negro-Balmaseda JJ, Mínguez-Mosquera MI, Cascajo-Almenara MV and Garrido-Fernandez J. Astaxanthin from crayfish (Procambarus clarkii) as a pigmentary ingredient in the feed of laying hens. Grasas Y Aceites, 59: 139-145. 2008.

Reis LH, Gama LT and Soares CM. Effect of short storage conditions and broiler breeder age on hatchability, hatching time, and chick weights. Poultry Science, 76: 1459-1466. 1997.

Shimidzu N, Goto M and Miki W. Carotenoids as singlet oxygen quenchers in marine organisms. Fisheries Science, 62: 134137. 1996.

Surai PF and Speake BK. Distribution of carotenoids from the yolk to the tissues of the chick embryo. Journal of Nutritional Biochemistry, 9: 645-651. 1998.

Surai PF, Speake BK and Sparks NHC. Carotenoids in avian nutrition and embryonic development. 2. Antioxidant properties and discrimination in embryonic tissues. Journal of Poultry Science, 38: 117-145. 2001.

Surai AP, Surai PF, Steinberg W, Wakeman WG, Speake BK and Sparks NHC. Effect of canthaxanthin content of the maternal diet on the antioxidant system of the developing chick. British Poultry Science, 44: 612-619. 2003.

Vleck CM and Bucher TL. Energy metabolism, gas exchange, and ventilation. Pages 89-116 in Avian growth and development: evolution within the altricial-precocial spectrum. Starck JM and Ricklefs RE eds. Oxford University Press. Oxford. 1998.

Yang YX, Kim YJ, Jin Z, Lohakare JD, Kim CH, Ohh SH, Lee SH, Choi JY and Chae BJ. Effects of dietary supplementation of astaxanthin on production performance, egg quality in layers and meat quality in finishing pigs. Asian-Australasian Journal of Animal Sciences, 19: 1019-1025. 2006. 